\title{
ALGUMAS NOTAS SOBRE A OBRA DE CHALÁMOV NO CAMPO DA CRÍTICA
}

\section{Andrea Zeppini Menezes da Silva ${ }^{1}$}

Resumo: Varlam Chalámov foi um escritor russo que passou dezessete anos em campos do Gulag. Escreveu sua principal obra, os seis volumes de Contos de Kolimá, sobre essa experiência. Seus primeiros contos são de 1954 e os últimos datam do início da década de 70: trabalhou durante vinte anos nessa obra colossal que foi censurada, mutilada, proibida. A publicação integral dos contos em seu país, da maneira como foi pensada pelo escritor, só aconteceu depois de sua morte, no final da década de 80 . Até então, ela circulava apenas no exterior ou em publicações ilegais na Rússia. O presente trabalho busca apresentar algumas notas sobre a obra de Chalámov no contexto da crítica e do difícil caminho para sua publicação.

Palavras-chave: Varlam Chalámov; Gulag; crítica literária

\begin{abstract}
Varlam Chalámov was a Russian writer who spent seventeen years in Gulag camps. He wrote his main work, the six volumes of Kolyma Tales, about this experience. His first tales are from 1954 and the last ones from the beginning of the 70's: he worked for twenty years in this colossal ouvre that was censored, mutilated, prohibited. The complete publication of the short stories in his country, as they were planned by the writer, only happened after his death, in the late 80's. Until then, they circulated only abroad or in illegal publications in Russia. This paper aims to present some notes about the work of Chalámov in the context of the criticism and the difficult path for its publication.
\end{abstract}

Keywords: Varlam Shalamov; Gulag; literary criticism.

1 Doutora em Literatura e Cultura Russa pela Universidade de São Paulo. Possui Mestrado e Graduação pela mesma instituição. E-mail: dedazeppini@hotmail.com 
Chalámov, escritor russo, nascido em Vólogda em 18 de junho 1907, passou dezessete anos de sua vida como prisioneiro no Gulag e sobre essa experiência escreveu sua principal obra. Contos de Kolimá constitui-se por seis ciclos de contos que mesclam memória, ficção, história, literatura. Além dos contos, escreveu cartas, ensaios, peças de teatro e muita poesia. Preso pela primeira vez em 1929 por fazer oposição ao regime, solto em 1932, cai novamente nas garras de Stálin em 1937, sendo mandado para Kolimá, um dos piores campos do Gulag, no extremo leste da Sibéria, onde as temperaturas chegavam a sessenta graus negativos e o cuspe congelava no ar. Chalámov passou por prisões, minas de ouro e carvão, pelos limites da crueldade humana, do trabalho extenuante e fatal, por condições impensáveis de frio, fome, humilhações constantes, surras diárias. Kolimá mostrou a Chalámov os limites humanos, chegando bem perto de levá-lo à morte por diversas vezes; mas forjou também um escritor intenso, brilhante, de prosa seca e poética, onde a dor latente pulsa muda, poderosa e explode em poesia. Chalámov foi um poeta, até mesmo quando escrevia prosa. Já conseguia compor versos nos últimos anos de Kolimá, quando trabalhava como enfermeiro no campo, já fora do mortal trabalho nas minas, mas os contos só começam a sair em 1954, logo depois do término de sua pena.

O presente trabalho trata da relação complicada entre Contos de Kolimá e a crítica. O escritor morreu em 1982, cego, surdo, meio louco, abandonado, tendo vivido na pobreza e na obscuridade, sem ver realizado o grande desejo de ver seus contos publicados oficialmente em seu país. O que viu foi apenas a publicação esparsa de alguns contos mutilados por correções dos "editores", tanto em samizdat (parte da luta dissidente contra o regime: veiculação de manuscritos não autorizados que toma corpo a partir dos anos 60), como em tamizdat (veiculação de obras, não autorizadas oficialmente, no exterior). Obra difícil de ser lida, tanto pelo tema quanto pela densidade e concisão, a alta qualidade literária de sua prosa não encontrou uma crítica receptiva no início: os anos 60 já estavam saturados de Soljenítsin. O percurso da publicação e da recepção crítica de Contos de Kolimá narra narra uma história árida e árdua, de destituição de direitos e luta pelo controle da própria obra, como se o Gulag se perpetuasse na trajetória do escritor, ainda que de outras formas, até o fim da vida. Neste trabalho, nos concentraremos no diálogo entre o pensamento de Chalámov e as primeiras críticas a respeito de sua obra, escritas nos anos 60, pois nelas já se encontram elementos que vão marcar a recepção posterior de sua escrita. Também abordaremos a publicação de seus contos no exterior e a recepção crítica na própria Rússia, já entre o final dos anos 80 e início dos 90, época em que Chalámov começou a ser publicado no país.

Começamos essa história em 1962, em pleno "degelo", época de relativa abertura política que veio na esteira do discurso de Khruschev no XX Congresso do Partido, em 1956. Em $1^{\circ}$ de novembro de 1962, por uma decisão do XXII Congresso do Partido, o corpo de Stálin foi retirado do mausoléu. 1962 também foi o ano de publicação de Um dia na vida de Ivan Denísovitch, de Soljenítsin, primeira obra sobre o "tema do campo" publicada oficialmente no período soviético, que saiu no número de novembro da revista "Novo Mundo" (Novi Mir). A partir desses dois eventos, Chalámov entendeu que era a hora e a vez de seus contos. Em 12 de novembro, entregou os do primeiro ciclo a Tvardóvski, editor do "Novo Mundo", onde Chalámov trabalhava como revisor interno desde 1959. Em 27 de novembro, 
entregou-os também para o "Escritor Soviético" (Sovietski Pissátiel), publicação onde já saíra, em 1961, sua primeira coletânea de poesias, recebida com bastante sucess (ESIPOV s.d.).

A negativa de Tvardóvski veio rápida e foi sentida agudamente por Chalámov: a justificativa era que Um dia na vida de Ivan Denísovitch teria esgotado o tema do campo. Já a recusa do "Escritor Soviético" veio apenas depois de um ano e meio, em 30 de julho de 1964. As críticas internas a propósito da publicação dos contos, que vieram a lume a partir de pesquisas recentes nos arquivos da revista, permitem uma melhor compreensão dos caminhos da obra pelo contexto ideológico do país, dos motivos pelos quais ela não conseguiu ser publicada na época (SOLOVIOV. 2015).

A primeira crítica é de Olieg Volkov, escrita ainda em 1962. Volkov, na época de Stálin, fora preso cinco vezes, condenado a mais de 25 anos de pena, cumprida em prisões, campos e no exílio, o que lhe dava, no mínimo, um olhar sensível para o tema. Impactado pela leitura dos contos, o crítico recomenda fortemente sua publicação, enfatizando a obra de Chalámov como documento de terror escrito por um sobrevivente. As qualidades artísticas da obra são mencionadas só secundariamente. Depois da publicação de Um dia na vida de Ivan Denísovitch, Soljenítsin se torna a grande referência no que diz respeito ao tema do campo. Ao comparar essa obra com a de Chalámov, Volkov lança as bases de uma discussão que será desenvolvida pela crítica nos próximos anos (SOLOVIOV. 2015). Nessa primeira crítica de que se tem notícia sobre a obra de Chalámov, bem longe de imaginar que a obra de Soljenítsin tenha esgotado o tema do campo, o crítico aborda um tema fundamental de diferenciação entre os dois, que é a espinhosa questão sobre o trabalho. Se no campo de Soljenítsin é possível realizar um trabalho honesto, é possível até mesmo se empolgar com o trabalho, nos contos de Chalámov este é destruidor: os prisioneiros aprendem a odiar o trabalho, fugindo dele como podem, fingindo doenças e chegando ao extremo da automutilação, na luta desesperada pela sobrevivência. Um exemplo citado pelo crítico é o conto "Chuva", onde o trabalho de cavar buracos debaixo de uma chuva fininha que gela os ossos, onde o prisioneiro não tem como se secar nem para dormir, é enlouquecedor e leva ao suicídio (VOLKOV. 1962).

Volkov nota que Chalámov trata do campo sim, mas, mais do que isso, trata do homem, do que é humano, para além e aquém do arame farpado. Trata do que o campo faz com o homem, o que este se torna, psicologicamente, quando submetido às mais árduas circunstâncias, à total destituição de sua humanidade. Notamos aqui a sensibilidade do crítico para os propósitos do autor que buscava, através de sua obra, fazer uma "investigação artística de um tema terrível”, mostrar as "novas leis psicológicas, o que há de novo no comportamento do homem quando rebaixado à condição animal" (CHALÁMOV. 2016. P. 395). Para o crítico, o leitor perceberia logo que o homem mostrado no campo, esse homem que já não é mais homem, humilhado além dos limites ou investido de um poder desmedido, é o homem produzido pelas condições do campo. Vê no conto "Serafim" um exemplo de tomada de consciência: um trabalhador livre é confundido com um detento e, ao entrar em contato com a violência do mundo do campo, não aguenta continuar vivendo (VOLKOV. 1962). O crítico parece ter se aproximado do significado do campo para Chalámov, que considerava "a experiência do campo negativa para o homem, desde a primeira até a última hora. O homem não deveria saber, não deveria nem mesmo ouvir falar sobre isso”. O cam- 
po seria apenas "uma escola negativa, uma degradação para todos" (CHALÁMOV. 2016. P. 396).

Ao recomendar a obra para a publicação, o crítico vê na qualidade artística de Chalámov apenas a utilidade como denúncia de uma situação terrível. Faz referência ainda aos "erros" e "repetições" presentes no texto, remediáveis, segundo ele, por uma rápida edição. O crítico recomenda também a supressão de um dos contos, "A primeira morte", por ser de qualidade inferior aos outros, segundo ele, e pela repetição do tema (VOLKOV. 1962). Essas observações atestam o que está patente no ensaio todo: o crítico sentiu a força da escrita de Chalámov, mas pelo aspecto do documento, sem atentar, verdadeiramente, para o aspecto inovador de sua prosa. Interessante retomar aqui o que o próprio autor pensava a respeito desses "erros" e "repetições": não eram erros nem repetições simplesmente, mas liberdade de criação. Diz ele: "Todas as repetições, todos os lapsos de que os leitores me acusam foram feitos por mim não por acaso, não por descuido, não por pressa..." Há uma intenção: "A própria autenticidade, a primazia, exige esse tipo de erro" (CHALÁMOV. 2016. P. 406). Emprestando da poesia a ideia de que a primeira variante é a única que vale, o "erro" e a não correção são pontos fundamentais para a concepção artística do escritor: "Todos os que escrevem versos sabem que a primeira variante é mais sincera, mais espontânea, que obedece à pressa de expressar o essencial. $\mathrm{O}$ acabamento posterior, a correção (em diversos sentidos), é controle, violência do pensamento sobre o sentimento, intervenção do pensamento" (CHALÁMOV. 2016. P. 406).

Depois da crítica de Volkov, Victor Fogelson, editor das cinco coletâneas de poesias de Chalámov publicadas entre 1961 e 1975, pede ajuda a uma crítica conhecida por ajudar escritores de difícil publicação. Elvina S. Moroz, impactada com a leitura, também recomenda a obra para a publicação, dizendo, contudo, que a posição do autor é inaceitável, pois este parece não amar seus personagens nem as pessoas em geral: nos contos de Chalámov, todos seriam privados de humanidade (SOLOVIOV. 2015). Como Volkov, Moroz destaca o conteúdo dos contos como argumento para a publicação: para a crítica é importante que os horrores dos campos sejam conhecidos pelo público. Para Chalámov, mais do que isso, contar o que acontecia nos campos era um dever:

A necessidade desse tipo de documento é extraordinariamente grande. Pois em cada família, tanto na aldeia quanto na cidade, entre a intelligentsia, trabalhadores e camponeses, havia pessoas _ ou parentes, ou conhecidos _ que pereceram na prisão. É justamente esse leitor russo, e não apenas russo, que espera de nós uma resposta (CHALÁMOV. 2016. P. 396)

Para o escritor, "o tema do campo em sua interpretação ampla, em sua compreensão profunda, é a questão fundamental, essencial de nossos dias" (CHALÁMOV. 2016. P. 408).

A terceira crítica, esta sim definitiva para o destino de Contos de Kolimá, é de A.K. Dremov (1963), que segue a linha do partido. Ele lembra que Khruschev recomenda que o "tema do campo" seja tratado com muito cuidado, pois não deve minar no leitor a fé no homem, em sua força e possibilidades. Nesse sentido, para o crítico, a obra de Soljenítsin mostraria o homem que se mantém homem nas condições mais adversas, enquanto a de 
Chalámov mostraria a destruição inevitável. Para o crítico, que também olha para os contos da perspectiva de seu conteúdo, as personagens de Chalámov não se diferenciariam: a única diferenciação existente seria entre os "blatares" (uma das denominações para os criminosos) e os outros presos, que são mostrados apenas como mortos de fome, sofrendo com as doenças, as surras, as humilhações. Nem Elvina Moroz nem Dremov conseguiram penetrar no sentido da representação dos presos em Contos de Kolimá, onde "são mostradas pessoas sem biografia, sem passado e sem futuro” (CHALÁMOV. 2016. P. 396). Sim, o campo animaliza, é o que Chalámov busca mostrar.

A conclusão a que chega o crítico é, no mínimo, curiosa: publicar esses contos seria um erro, pois não teriam utilidade para ninguém. Apesar da verossimilhança, não corresponderiam à verdade da vida, à verdade da arte. Termina apontando alguns contos que considera publicáveis em uma coletânea de vários autores. Notamos que são contos que não trazem o horror do dia a dia no campo, mais leves: "Hércules" é uma sátira sobre o poder; "Stlánik" é uma descrição paisagística; "Pela Neve" é o conto-metáfora que abre a coletânea,

a integridade da composição é uma qualidade relevante em Contos de Kolimá. Nessa coletânea é possível substituir e mudar de lugar apenas alguns contos, mas os principais, os de base, devem estar em seus próprios lugares. Todos os que leram Contos de Kolimá integralmente, e não apenas contos isolados, disseram ter tido uma grande, forte impressão (CHALÁMOV. 2016. 403).

Nesse contexto, podemos imaginar o que sentiu Chalámov ao ver seus contos sendo publicados esparsamente, como unidades autônomas. A crítica de Dremov definiu o destino da obra: foi com base nela que o "Escritor Soviético" se recusou a publicar Contos de Kolimá, levando o público russo a conhecê-la apenas 25 anos depois. Ainda em 1967, mesmo desesperançado, Chalámov tenta publicar os Ensaios do mundo do crime, outro ciclo de contos, novamente sem sucesso (ESIPOV s.d.) Entre todos esses nãos, houve uma pequena exceção: o conto "Stlánik", já citado acima, foi publicado em 1965, na revista "Juventude Rural" (Sielskaia Molodioj). Trata-se de uma poética descrição paisagística, filosófica, tendo como protagonista uma árvore típica do norte, metáfora da resistência do preso, de sua força de vida. Chalámov chama esse conto de "pausa paisagística": na construção do ciclo Contos de Kolimá, ele é "necessário, não como informação paisagística, mas como estado de alma", ou seja, funciona como um pequeno respiro entre contos mais pesados, digamos assim, contos que relatam acontecimentos do campo (CHALÁMOV. 2016. P. 405). É sintomático que apenas "Stlánik" tenha sido publicado e que ele esteja incluído na lista de Dremov dos publicáveis: ele não conta a situação dos presos de Kolimá.

Na Rússia, a obra de Chalámov só começa a ser publicada oficialmente em 1988, quando seus contos começam a sair em jornais; no ano seguinte, saem em livro. Irina Niekrássova (2003) faz um apanhado das críticas dessa época, notando que, com algumas exceções, a maior parte dos autores se concentra na utilidade ou na não utilidade da obra, do ponto de vista do material; no impacto moral; na relação entre obra e biografia; na visão de mundo do autor. São pontos relevantes, sem dúvida, mas não dão conta de um aspecto muito significativo para Chalámov: sua poética. Alguns exemplos: Boris Lesniak (1989) trabalha 
com a perspectiva biográfica e literária, a força motriz de Contos de Kolimá seria uma raiva apaixonada, um sentimento de vingança pelos sonhos, esperanças e ambições espezinhados. Tudo o que está nos contos é verdadeiro, segundo esse autor, mas com uma coloração diferente. Atribui as contradições encontradas na obra à personalidade do autor, que costumava mudar de opinião o tempo todo. Segundo ele, Chalámov, mais do que sobre o campo, falava sobre seu tempo. Evgueni Shklovski (1991) busca investigar a visão de mundo do escritor, integrando o homem e o artista. Destaca seus valores éticos, sua capacidade de sacrifício e penitência. Os grandes temas seriam o povo e a intelligentsia, a a fé religiosa, a personalidade e seus critérios morais. Para M. Beriutti, o mundo artístico de Chalámov seria estruturado nas seguintes palavras: morte, ressurreição, eternidade, vida.

O trabalho de L. Timoféiev (1991) é um dos primeiros, e raros, em um primeiro momento, a se debruçar sobre as questões da poética: o crítico vê a morte como base da composição, estruturadora do tempo e do espaço, o campo como um espaço separado do mundo, o tempo sem presente, passado, futuro, o tempo do nada. E. Sidorov (1989) vê a causa do impacto provocado pela obra de Chalámov não no material, já que outros teriam escrito sobre a mesma coisa, mas na qualidade artística do escritor, que retrataria o campo de forma seca e direta, sem lamentações. E. Volkova (1997) destaca a presença de múltiplos planos, o não acabamento, a expansão do tempo e do espaço. Trifonov (1987) e Moltchánova (1991) ressaltam a simplicidade e a concisão, esta última ainda atenta para as frases iniciais dos contos, enérgicas e explosivas, e as finais, que carregam múltiplos significados. Concisão, simplicidade, narrativa "simples e clara daquilo que é de vital importância", "inserção de pormenores insólitos e novos, descrições feitas de um jeito novo", o uso de sinônimos e repetições para construir o ritmo da prosa, a alta carga semântica, o sentimento (pois apenas o sentimento pode "ressuscitar a vida"), a "pureza de tons", são alguns dos traços do que Chalámov chama de "nova prosa", que seria a literatura possível, e desejável, depois de Hiroshima, Auschwitz, Kolimá (CHALÁMOV. 2016. PP. 400-401). Além disso, a "nova prosa” deve ser escrita apenas por quem viveu o que escreve: "aquilo que foi sofrido na própria carne chega ao papel como um documento da alma, transfigurado e iluminado pelas chamas do talento" (CHALÁMOV. 2016. P. 406). Irina Sirotinskaia, a grande responsável pela conservação e divulgação da obra de Chalámov, sua grande amiga, herdeira e último amor, vê sua obra como uma mistura de memórias, autobiografia e forma literária.

Quanto à publicação fora da Rússia, depois da recusa de Tvardóvski, os contos, que já circulavam pelas mãos de amigos e conhecidos desde a década de 50, vazam para a samizdat e daí para o exterior. Segundo Esipov (s.d.), Chalámov não pretendia publicar suas obras no exterior, mas em 1966, ao que tudo indica, ele entrega seus manuscritos ao Professor Clarence Brown, da Universidade de Princeton. O professor leva essas cópias datilografadas aos EUA, entregando esses contos a uma revista de Nova York, que começa a publicá-los aos poucos, durante dez anos. Segundo seu editor, seria um pedido expresso de Chalámov (Gull, 2001). Mas a indignação do escritor diante dessa publicação que, além de mutilar sua obra, ainda o fazia parecer um funcionário da revista aos olhos da KGB, não confirma esse consentimento.

Depois de Nova York, os contos aparecem em publicações emigrèes na Alemanha Ocidental, onde saíram dispersamente durante vinte anos (GOLOVIZNIN. 2010). Chalámov 
ficou enfurecido: essas publicações, assim como a de Nova York, tinham orientação francamente antissoviética, eram mal-vistas na União Soviética e estavam usando seus contos como argumento no contexto da disputa ideológica da guerra fria. Essa indignação, e talvez o medo de ver seu nome ligado a essas publicações _ Chalámov sabia que era monitorado

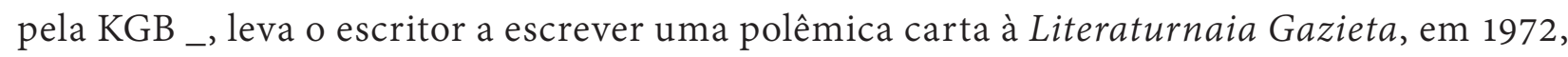
onde chega a dizer que o assunto do campo não era mais relevante. Esta carta causou uma ruptura sem volta entre Chalámov e os dissidentes (com quem o escritor já não simpatizava), aprofundando o isolamento em que caíra nos últimos anos de vida.

A primeira tradução da obra de Chalámov para outra língua acontece em 1968: para o alemão. A coletânea sai com erros grosseiros já desde o título: Artikel 58: Aufzichnungen des Häftlings Schalanow (Artigo 58: Apontamentos do Prisioneiro Chalánov). Além da grafia incorreta do nome e da tradução ruim, a edição não possui nenhum dado biográfico do autor e traz, como prefácio, a reprodução do parágrafo relativo ao artigo 58, do Código Penal da URSS. Há registros nos arquivos de Chalámov de que o escritor teria pedido à editora, sem sucesso, que lhe pagasse os honorários, pois nem ao menos lhe dera autorização para publicar seus contos (GOLOVIZNIN. 2010). Se Chalámov permaneceu desconhecido na Alemanha até a década de 90, hoje seu nome está estabelecido: sua obra desperta grande interesse do público, nas universidades é matéria de cursos e palestras.

As manifestações de maio de 68 em Paris, as greves nas fábricas, todo o contexto social e político da época instigaram a publicação de Contos de Kolimá na França, em 1969. Sob o título de Histórias de Kolimá ("Récits de Kolyma”), "Les Lettres Nouvelles" publica uma edição bem mais cuidada do que a alemã e com outros contos, traduzida a partir de uma fotocópia datilografada contrabandeada até as mãos do editor, com o consentimento de Chalámov, segundo sua versão. Pouco depois, a Gallimard também publica a obra do escritor, mas foi a reprodução em francês da primeira edição alemã, repetindo, inclusive, os mesmos erros.

Contos de Kolimá só passa a ser realmente considerada uma obra literária na publicação londrina da Overseas, de 1978, que a publica em russo e em versão integral. Curiosamente, seu editor recebe os textos e o direito de publicá-los (!), das mãos do editor da revista de Nova York que publicara o escritor pela primeira vez no exterior. Mark Geller, que colaborou na edição da Overseas, chega a escrever no prefácio que publicar os contos de Chalámov separadamente, como estavam fazendo até então, era a mesma coisa que picotar um quadro de Rembrandt (ESIPOV. s.d.).

Em 1980 sai nos EUA a coletânea Contos de Kolimá, seguida de Grafite (1981), muito bem recebidas pela crítica (GLAD. 2013): já há uma sensibilidade maior para qualidade literária da escrita de Chalámov. Nos últimos anos, já saíram edições integrais de Contos de Kolimá na Itália (Milão, Einaudi, 1999, tradução de Sergio Rapetti) e na Espanha (Barcelona, Minúscula, 2007-13, tradução de Ricardo San Vicente). No Brasil, até 2015, ano em que a Editora 34 começa a lançar a obra integral, havia apenas dois contos publicados em duas coletâneas.

No contexto do percurso da obra esboçado aqui, notamos que Chalámov é um escritor que ainda está sendo descoberto. Depois de passar pelo obstáculo da censura oficial, de servir como instrumento na luta ideológica da guerra fria, de ser preterida pela crítica em 
favor da obra de Soljenítsin (mais palatável e menos perigosa ideologicamente), de ser vista apenas como testemunho de uma das páginas mais cruéis da história, a obra de Chalámov é agora vista como obra de um artista. Não só isso: um artista genial. É uma pena ele não estar aqui para ver.

\section{REFERÊNCIAS}

CHALÁMOV, Varlam. "Sobre a prosa" in CHALÁMOV, Varlam. O Artista da Pá, Sâo Paulo: Editora 34. 2016.

DREMOV, Anatoli. "Retsensia na rukopis 'kolimskikh raskazov"” (resenha sobre o manuscrito “Contos de Kolimá”). 1963. Disponível em http://www.shalamov.ru/critique/80/

ESIPOV, Valeri. "Protsies umoltchania" ("Processo de silêncio"). Disponível em http://www.shalamov. $\mathrm{ru} / \mathrm{critique} / 283 /$

GLAD, John. "Ob isdaniakh I perevodakh chalamova v amerique" ("Sobre as edições e traduções de Chalámov na América”). 2013. Disponível em http://www.shalamov.ru/critique/285/

GOLOVIZNIN, Mark. "Ka vaprossu o proiskhoxdienikh za rubiexnikh izdani kolimskikh raskazi v t chalamova" ("Sobre a origem das primeiras edições estrangeiras de contos de kolimá, de varlam chalamov"). 2010. disponível em http://shalamov.ru/research/219/

GULL, Roman. "Vospominania o publikatsi 'kolimskikh raskazov' v 'novom jurnale' ("Memórias sore a publicação de Contos de Kolimá na 'Nova Revista”'). 2001. Disponível em http://www.shalamov.ru/ memory/161/.

NIEKRÁSSOVA, Irina. Sudba e tvortchestva Varlama Chalamova (Destino e criação de Varlam Chalámov). 2003. Disponível em http://www.shalamov.ru/research/158/2.html

SOLOVIOV, Sergei. "Olieg Volkov _ piervi retsenzent kolimskikh rasskazov" (“Olieg Volkov: primeira resenha de contos de Kolimá”). 2015. Disponível em http://www.shalamov.ru/research/265/

SOLOVIOV, Sergei; GALKOVA, Irina; MIEDVIEDIEV, Sergei. "Kolimski prorok. Varlam Chalámov kak sviditiel ada. Biecieda v programe arkheologia na rádio svaboda" ("O profeta de Kolimá. Varlam Chalámov como testemunha do inferno. Conversa no programa "arqueologia" na rádio liberdade"). 2016. Disponível em http://www.shalamov.ru/critique/289/

VOLKOV, Olieg. "Vnutrenaia retzenzia na 'kolimskie raskazi' dlia isdatielstva 'sovietski pissatiel' ("Resenha interna sobre "Contos de Kolimá" para a publicação "Escritor Soviético"). 1962. Disponível em http://shalamov.ru/critique/266/ 